\title{
Báo chí nói gì về biến đổi khí hậu: Câu chuyện từ hơn 37 nghìn bài báo
}

\author{
Nguyễn Thanh Dung (SSHPA) \\ Khoa học \& Phát triển
}

KH\&PT (16/01/2020; http://khoahocphattrien.vn/khoa-hoc/bao-chi-noi-gi-ve-bien-doikhi-hau-cau-chuyen-tu-hon-37-nghin-bai-bao/20200116101152456p1c160.htm) Truyền thông ở những quốc gia có GDP cao thường coi biến đổi khí hậu là vấn đề quốc gia hoặc vấn đề khoa học, trong khi các nước nghèo thường nhắc tới quan hệ ngoại giao và tác động tự nhiên của nó, theo một nghiên cứu của Việt Nam được công bố trên tạp chí quốc tế có hệ số tác động JIF>10.

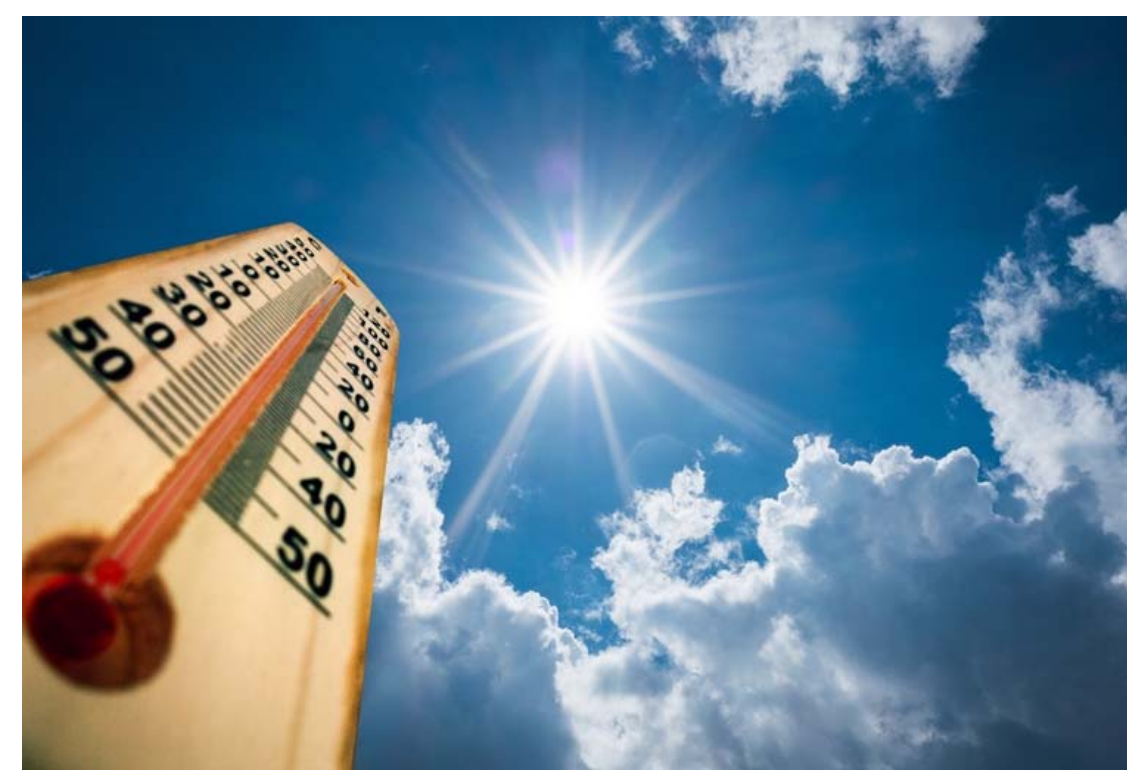

Minh họa: KH\&PT (16/01/2020)

Báo chí đóng vai trò quan trọng trong việc phổ cập kiến thức về các vấn đề kinh tế - xã hội tới người dân, đặc biệt là các vấn đề gây nhức nhối như biến đổi khí hậu. Tuy biến đổi khí hậu đã trở thành một vấn đề toàn cầu, truyền thông ở mỗi quốc gia lại có những cách đưa tin khác nhau. ở một mảnh đất chưa được quá nhiều nghiên cứu khai phá, công bố Nationalizing a global phenomenon: A study of how the press in 45 countries and territories portrays climate change của các tác giả Vũ Hồng Tiến (tác giả liên lạc), Yuchen Liu (Đại học Kansas, Hoa Kỳ) và Trần Đức Vinh (Đại học Bách khoa Hà Nội) về vấn đề truyền thông và biến đổi khí hậu đã xuất hiện trên tạp chí Global Environmental Change [JIF 2018 = 10.427; CiteScore $2018=10.29$ ] 
Nghiên cứu nói trên phân tích mối quan hệ giữa các yếu tố kinh tế - xã hội, chính trị, môi trường và nội dung truyền thông về biến đổi khí hậu trong 37.670 bài báo, sử dụng 4 ngôn ngữ khác nhau, trên 45 quốc gia toàn cầu trong giai đoạn 2011 - 2015.

Kết quả cho thấy biến đổi khí hậu thường được đề cập trên 7 khía cạnh: bằng chứng khoa học, vấn đề năng lượng, tác động tự nhiên, tác động kinh tế, chính sách đối nội, quan hệ đối ngoại và tiến bộ xã hội. Trong đó, quan hệ đối ngoại được đề cập nhiều nhất do biến đổi khí hậu đã trở thành một vấn đề toàn cầu. Ngay sau đó là tác động kinh tế của biến đổi khí hậu. Trong khi đó, hai vấn đề quan trọng khác là bằng chứng khoa học và năng lượng lại được đề cập rất ít trong giai đoạn dữ liệu.

Yếu tố vĩ mô đóng vai trò quan trọng trong việc định hình nội dung của các bài báo về vấn đề biến đổi khí hậu. Truyền thông ở những quốc gia có GDP cao thường coi biến đổi khí hậu là vấn đề quốc gia hoặc vấn đề khoa học, trong khi các nước nghèo thường nhắc tới quan hệ ngoại giao và tác động tự nhiên của biến đổi khí hậu.

Các tác giả cho rằng điều này xuất phát từ việc các nước nghèo không có đủ ngân sách cho các hoạt động nghiên cứu và thường phải nhờ tới nguồn viện trợ của nước ngoài. Ngoài ra, các nước chịu ảnh hưởng bởi khí hậu cực đoan cũng thường đề cập tới tác động tự nhiên của biến đổi khí hậu.

Nghiên cứu đã có những đóng góp quan trọng cho lĩnh vực nghiên cứu truyền thông, đặc biệt là về sự khác nhau trong thực hành báo chí. Sự khác nhau về văn hóa, chính trị, kinh tế đã có những tác động không nhỏ tới cách thức truyền thông của từng quốc gia đưa tin về một vấn đề. Trong khi ảnh hưởng từ tổ chức hay cá nhân nhà báo tới thông điệp truyền thông đã có các bằng chứng thực nghiệm từ lâu thì nghiên cứu về ảnh hưởng từ bối cảnh văn hóa xã hội vẫn còn khiêm tốn, và bài viết này đã góp phần gợi ý một hướng nghiên cứu đáng quan tâm.

Bài báo của nhóm tác giả Vũ Hồng Tiến là 1 trong 14 bài nghiên cứu KHXH\&NV của các tác giả Việt Nam được công bố trên các tạp chí có hệ số tác động JIF > 5 trong năm 2019 (tăng 4 bài so với năm 2018), và là một trong hai bài được công bố trên tạp chí có JIF > 10.

Bảng dưới đây cung cấp thông tin về những bài báo có JIF > 6 trong năm qua. 


\begin{tabular}{|c|c|c|c|}
\hline Bài báo & Tạp chí & NXB & JIF \\
\hline $\begin{array}{l}\text { Breaking barriers in publishing } \\
\text { demands a proactive attitude }\end{array}$ & $\begin{array}{l}\text { Nature Human } \\
\text { Behaviour }\end{array}$ & $\begin{array}{l}\text { Nature } \\
\text { Publishing } \\
\text { Group }\end{array}$ & 10.575 \\
\hline $\begin{array}{l}\text { Nationalizing a global } \\
\text { phenomenon: A study of how } \\
\text { the press in } 45 \text { countries and } \\
\text { territories portrays climate } \\
\text { change }\end{array}$ & $\begin{array}{l}\text { Global } \\
\text { Environmental } \\
\text { Change }\end{array}$ & Elsevier & 10.427 \\
\hline $\begin{array}{l}\text { Promoting adoption of } \\
\text { management practices from } \\
\text { the outside: Insights from a } \\
\text { randomized field experiment }\end{array}$ & $\begin{array}{l}\text { Journal of } \\
\text { Operations } \\
\text { Management }\end{array}$ & Wiley & 7.776 \\
\hline $\begin{array}{l}\text { Modeling home composting } \\
\text { behavior toward sustainable } \\
\text { municipal organic waste } \\
\text { management at the source in } \\
\text { developing countries }\end{array}$ & $\begin{array}{l}\text { Resources, } \\
\text { Conservation } \\
\text { and Recycling }\end{array}$ & Elsevier & 7.044 \\
\hline $\begin{array}{l}\text { Growth of low emission- } \\
\text { intensive energy production } \\
\text { and energy impacts in } \\
\text { Vietnam under the new } \\
\text { regulation }\end{array}$ & $\begin{array}{l}\text { Journal of } \\
\text { Cleaner } \\
\text { Production }\end{array}$ & Elsevier & 6.395 \\
\hline $\begin{array}{l}\text { Sustainable development and } \\
\text { environmental policy: The } \\
\text { engagement of stakeholders } \\
\text { in green products in Vietnam }\end{array}$ & $\begin{array}{l}\text { Business } \\
\text { Strategy and } \\
\text { the } \\
\text { Environment }\end{array}$ & Wiley & 6.381 \\
\hline
\end{tabular}




\begin{tabular}{|c|c|c|c|}
\hline $\begin{array}{l}\text { Establishing a tobacco control } \\
\text { fund in Vietnam: some } \\
\text { learnings for other countries }\end{array}$ & $\begin{array}{l}\text { Tobacco } \\
\text { Control }\end{array}$ & BMJ & 6.221 \\
\hline $\begin{array}{l}\text { Can diversity climate shape } \\
\text { service innovative behavior in } \\
\text { Vietnamese and Brazilian tour } \\
\text { companies? The role of work } \\
\text { passion }\end{array}$ & $\begin{array}{l}\text { Tourism } \\
\text { Management }\end{array}$ & Elsevier & 6.012 \\
\hline
\end{tabular}

\section{Tài liệu tham khảo:}

Le Van, Q., Viet Nguyen, T., \& Nguyen, M. H. (2019). Sustainable development and environmental policy: The engagement of stakeholders in green products in Vietnam. Business Strategy and the Environment, 28(5), 675-687.

Luu, T. T. (2019). Can diversity climate shape service innovative behavior in Vietnamese and Brazilian tour companies? The role of work passion. Tourism Management, 72, 326-339.

Ngan, T. T., Huyen, D. T., Van Minh, H., \& Wood, L. (2019). Establishing a tobacco control fund in Vietnam: some learnings for other countries. Tobacco control, tobaccocontrol-2019.

Nguyen, Q., \& Kim, T. H. (2019). Promoting adoption of management practices from the outside: Insights from a randomized field experiment. Journal of Operations Management, 65(1), 48-61.

Nong, D., Siriwardana, M., Perera, S., \& Nguyen, D. B. (2019). Growth of low emissionintensive energy production and energy impacts in Vietnam under the new regulation. Journal of Cleaner Production, 225, 90-103.

Takahashi, Y., Nomura, H., \& Yabe, M. (2019). Modeling home composting behavior toward sustainable municipal organic waste management at the source in developing countries. Resources, Conservation and Recycling, 140, 65-71. 
Vu, H. T., Liu, Y., \& Tran, D. V. (2019). Nationalizing a global phenomenon: A study of how the press in 45 countries and territories portrays climate change. Global Environmental Change, 58, 101942, DOI:10.1016/j.gloenvcha.2019.101942.

Vuong, Q. H. (2019). Breaking barriers in publishing demands a proactive attitude. Nature Human Behaviour, 3(10), 1034-1034. 